\title{
Antimicrobial and cytotoxic effects of phosphoric acid solution compared to other root canal irrigants
}

\author{
Maíra PRADO, Emmanuel João Nogueira Leal da SILVA, Thais Mageste DUQUE, Alexandre Augusto ZAIA, Caio \\ Cezar Randi FERRAZ, José Flávio Affonso de ALMEIDA, Brenda Paula Figueiredo de Almeida GOMES
}

Department of Restorative Dentistry, Endodontics Division, Piracicaba Dental School, State University of Campinas - UNICAMP, Piracicaba, SP, Brazil.

Corresponding address: Brenda P.F.A. Gomes - Faculdade de Odontologia de Piracicaba - UNICAMP - Departamento de Endodontia - Av. Limeira, 901 Areião - Piracicaba - São Paulo - Brazil - 13414-903 - e-mail: bpgomes@fop.unicamp.br - Phone: (55) 1921065343 - Fax: (55) 1921065218

Submitted: January 8, 2014 - Modification: July 20, 2014 - Accepted: July 29, 2014

\section{ABSTRACT}

\begin{abstract}
Dhosphoric acid has been suggested as an irrigant due to its effectiveness in removing the smear layer. Objectives: The purpose of this study was to compare the antimicrobial and cytotoxic effects of a $37 \%$ phosphoric acid solution to other irrigants commonly used in endodontics. Material and Methods: The substances 37\% phosphoric acid, 17\% EDTA, $10 \%$ citric acid, $2 \%$ chlorhexidine (solution and gel), and $5.25 \% \mathrm{NaOCl}$ were evaluated. The antimicrobial activity was tested against Candida albicans, Staphylococcus aureus, Enterococcus faecalis, Escherichia coli, Actinomyces meyeri, Parvimonas micra, Porphyromonas gingivalis, and Prevotella nigrescens according to the agar diffusion method. The cytotoxicity of the irrigants was determined by using the MTT assay. Results: Phosphoric acid presented higher antimicrobial activity compared to the other tested irrigants. With regard to the cell viability, this solution showed results similar to those with $5.25 \% \mathrm{NaOCl}$ and $2 \%$ chlorhexidine (gel and solution), whereas 17\% EDTA and 10\% citric acid showed higher cell viability compared to other irrigants. Conclusion: Phosphoric acid demonstrated higher antimicrobial activity and cytotoxicity similar to that of $5.25 \% \mathrm{NaOCl}$ and $2 \%$ chlorhexidine (gel and solution).
\end{abstract}

Keywords: Phosphoric acids. EDTA. Citric acid. Chlorhexidine. Products with antimicrobial action. Toxicity test.

\section{INTRODUCTION}

Mechanical instrumentation during endodontic therapy produces an amorphous irregular layer known as smear layer. The smear layer consists of remnants of ground dentin, odontoblastic processes, pulp tissue, and microorganisms in the case of infected teeth ${ }^{10}$. It forms a barrier between filling material and sound dentin, which inhibits the penetration of irrigants into dentinal tubules, increases the microleakage of commonly used sealers, and decreases the bond strength of resinbased materials ${ }^{12,13,19}$.

Some chemical agents such as EDTA (ethylenediaminetetraacetic acid) solutions at concentrations ranging from 15 to $17 \%$, citric acid (5-50\%), and phosphoric acid (5-37\%) are used to remove this layer ${ }^{1,12,20,22}$.

Phosphoric acid at $37 \%$ is a substance commonly used in restorative dentistry for the conditioning of both enamel and dentin in the coronal surface. Its use in endodontics for smear layer removal showed favorable results. In a 3-minute application in the apical third, this solution was more effective than $17 \%$ EDTA and $10 \%$ citric acid ${ }^{12}$. Additionally, it was observed that when this solution was associated with $\mathrm{NaOCl}$, the bond strength of gutta-percha/AH Plus was improved as well as when associated with $\mathrm{CHX}$ for Resilon/Real Seal SE systems ${ }^{13}$. Although this solution has shown favorable results, assessing other characteristics such as its cytotoxic and antimicrobial effects is clinically required in the endodontic practice.

The purpose of this study was to compare the antimicrobial and cytotoxic effects of $37 \%$ phosphoric acid solution to other irrigants commonly used in endodontics. 


\section{MATERIAL AND METHODS}

\section{Root canal irrigants}

The substances evaluated in the present study were $37 \%$ phosphoric acid, 17\% EDTA, 10\% citric acid, $5.25 \% \mathrm{NaOCl}$, and $2 \%$ chlorhexidine (solution and gel). The same drugstore provided all these substances (Drogal, Piracicaba, SP, Brazil).

\section{Antimicrobial assay}

\section{Microorganisms}

The species of microorganisms Candida albicans (ATCC 10556), Staphylococcus aureus (ATCC 25923), Enterococcus faecalis (ATCC 29212), and Escherichia coli (ATCC 25922) were grown on 5\% brain heart infusion agar plates (BHI, Lab M, Bury, UK), whereas Actinomyces meyeri (ATCC 33972), Parvimonas micra (ATCC 33270), Porphyromonas gingivalis (ATCC 49417) and Prevotella nigrescens (ATCC 33563) were grown on fastidious anaerobe agar plates (FAA, Lab M, Bury, UK). In both media, $5 \%$ defibrinated sheep blood was added.

\section{Agar diffusion method}

The methodology used was adapted from Gomes, et al. ${ }^{7}$ (2002). All microorganisms were previously subcultured in appropriate culture media and under gaseous conditions to confirm their purity.

The aerobic (C. albicans) and facultative anaerobic strains ( $E$. coli, S. aureus, E. faecalis) were individually inoculated into tubes containing $5 \mathrm{~mL}$ of sterile saline solution. The suspension was adjusted spectrophotometrically at $800 \mathrm{~nm}$ (Optical Density 800 ) to match the turbidity of $1.5 \times 10^{8} \mathrm{CFU} /$ $\mathrm{mL}$ (equivalent to $0.5 \mathrm{McFarland}$ standard). Fivehundred $\mathrm{mL}$ of each test microorganism suspension were used to inoculate glass bottles containing $50 \mathrm{~mL}$ of BHI Agar (Lab M, Bury, UK) at $46^{\circ} \mathrm{C}$ before being mixed and poured onto $150 \mathrm{~mm}$ plates containing a previously set layer of Mueller Hinton agar (Oxoid, Unipath Ltd, Basingstoke, Hampshire, UK).

The strict anaerobic microorganisms ( $A$. meyeri, $P$. micra, $P$. gingivalis, $P$. nigrescens) were suspended spectrophotometrically at $800 \mathrm{~nm}$ to match the turbidity of $3.0 \times 10^{8} \mathrm{CFU} / \mathrm{mL}$ (equivalent to 1 McFarland standard). Sterile swabs were dipped into the microbial suspension and were used to inoculate pre-reduced $150 \mathrm{~mm}$ plates containing 5\% sheep blood fastidious anaerobe agar (FAA - Lab-M, Bury, Lancs, UK). The inoculation procedures used were appropriate to provide a semi-confluent growth of the microorganisms being tested ${ }^{6,7}$.

Three sterilized stainless steel tubes of $8.0 \times 1.0 \times 10.0 \mathrm{~mm}$ were added to the surfaces of the media and filled with $0.2 \mathrm{~mL}$ of each pure or composite substance. The plates were maintained for 2 hours at room temperature and appropriate gaseous conditions to allow for diffusion of the agents through agar and then incubated at $37^{\circ} \mathrm{C}$ again under appropriate gaseous conditions for the following periods of time: aerobes, 24 hours; facultative anaerobes, 24-48 hours in a $\mathrm{CO}_{2}$ incubator (Jouan $\mathrm{SA}$, Thermo Fisher Scientific, Saint Herblain, LoireAtlantique, France) in an atmosphere of $10 \% \mathrm{CO}_{2}$; and anaerobes in anaerobic workstation (Don Whitley Scientific, Bradford, West Yorkshire, UK) in an atmosphere of $10 \% \mathrm{H}_{2}, 10 \% \mathrm{CO}_{2}, 80 \% \mathrm{~N}_{2}$ for 7 days.

Zones of inhibition of microbial growth around the cylinder containing the tested substances were measured and recorded after the incubation period. The inhibitory zone was considered to be the shortest distance $(\mathrm{mm})$ between the outer margin of the cylinder and the initial point of the microbial growth. Three replicates were made for each microorganism.

\section{Cytotoxicity assay}

Balb/c 3T3 cells (American Tissue Type Collection, Manassas, VA, USA) were cultured in Dulbecco modified Eagle medium (DMEM) (Gibco, Grand Island, NY, USA), supplemented with $10 \%$ fetal bovine serum (Sigma Chemical Co, St Louis, MO, USA), $100 \mathrm{mg} / \mathrm{mL}$ streptomycin, and $100 \mathrm{mg} / \mathrm{mL}$ penicillin at $37^{\circ} \mathrm{C}$ in a humidified incubator in an atmosphere containing $5 \% \mathrm{CO}_{2}$. Confluent cells were detached with $0.25 \%$ trypsin and $0.05 \%$ EDTA for 5 minutes, with aliquots of separated cells being subcultured. Cells were seeded in 96-well plates ( $1 \times 10^{4}$ cells/well). After overnight attachment, cells were treated with various irrigants $(200 \mu \mathrm{L} /$ well $)$ for 30 minutes, which was representative of the clinical situation. Each irrigant was tested in a $1 / 1,1 / 10$, $1 / 100$ and $1 / 1000$ dilution with DMEM.

Cell viability was determined by using the 3-(4,5-dimethylthiazol-2-yl)-2,5diphenyltetrazolium bromide (MTT) assay. After removing the culture medium from each well, the cells were gently washed with phosphate-buffered saline. The wash was replaced with an MTT-succinate solution ( $1 \mathrm{mg} / \mathrm{mL}$; Sigma-Aldrich, St Louis, MO, USA) for 4 hours. After aspiration of the solution, the cell monolayers were rinsed with doubledistilled water, and then the water was completely removed. The formazan crystals produced within the cells, resulting from the succinate dehydrogenase reduction of MTT, were dissolved by using a destaining solution (isopropanol-10\%NP40-0.4N $\mathrm{HCl}$ ). The optical density (OD) of the solution contained in each well was determined by using an automatic microplate reader (Urit 660, Urit, Guillin Guanxi, China) at a wavelength of $495 \mathrm{~nm}$. Each experiment was performed using 3 cultures for each group and repeated 3 times. The formazan content of each well was computed as a percentage of the control group (untreated cells). 


\section{Statistical analysis}

The results were submitted to the KolmogorovSmirnov's test to evaluate the normal distribution. Antimicrobial data were analyzed with Kruskal-Wallis' and Mann-Whitney's tests $(p<0.05)$. Cytotoxicity data were analyzed with one-way analysis of variance (ANOVA) and Tukey's test $(p<0.05)$.

\section{RESULTS}

Table 1 shows the average and standard deviation values of growth inhibition zones (in $\mathrm{mm}$ ) produced by the substances against each tested microorganism. The in vitro antimicrobial effects of the substances were ranked from strongest to weakest as follows: $37 \%$ phosphoric acid, $17 \%$ EDTA, $10 \%$ citric acid, $5.25 \% \mathrm{NaOCl}, 2 \% \mathrm{CHX}$ gel, $2 \% \mathrm{CHX}$ solution. Statistical analyses showed that phosphoric acid presented higher antimicrobial effect than the other irrigants being tested (Figure 1).

The susceptibility of individual microorganisms to the substances was varied. Strict anaerobic microorganisms such as $P$. micra, $P$. gingivalis and $P$. nigrescens were more susceptible to the substances, while E. faecalis and C. albicans (facultative microorganisms) were more resistant (Figure 2).

Table 1- Average ( \pm Standard Deviation) area of the zones of microbial growth inhibition in $\mathrm{mm}$ provided by the tested substances against all microorganisms

\begin{tabular}{|c|c|c|c|c|c|c|}
\hline Groups & $\begin{array}{l}5.25 \% \\
\mathrm{NaOCI}\end{array}$ & $\begin{array}{l}2 \% \mathrm{CHX} \\
\text { solution }\end{array}$ & $2 \% \mathrm{CHX}$ gel & $17 \%$ EDTA & $\begin{array}{c}10 \% \text { Citric } \\
\text { acid }\end{array}$ & $\begin{array}{c}37 \% \\
\text { Phosphoric } \\
\text { acid }\end{array}$ \\
\hline C. albicans & $8.60 \pm 0.2$ & $8.20 \pm 0.8$ & $7.40 \pm 0.6$ & $6.00 \pm 0.2$ & $2.70 \pm 0.4$ & $8.80 \pm 2.6$ \\
\hline S. aureus & $4.90 \pm 0.8$ & $10.50 \pm 0.4$ & $9.10 \pm 0.4$ & $14.70 \pm 0.5$ & $8.10 \pm 0.5$ & $18.40 \pm 1.1$ \\
\hline E. faecalis & $2.60 \pm 0.4$ & $6.40 \pm 1.2$ & $6.20 \pm 0.3$ & $7.00 \pm 1.8$ & $4.90 \pm 1.8$ & $10.60 \pm 1.7$ \\
\hline E. coli & $9.40 \pm 0.8$ & $7.60 \pm 2.1$ & $5.90 \pm 1.1$ & $11.40 \pm 0.3$ & $7.90 \pm 1.1$ & $16.60 \pm 1.3$ \\
\hline A. meyeri & $7.90 \pm 0.1$ & $9.90 \pm 0.2$ & $10.10 \pm 1.1$ & $13.50 \pm 0.2$ & $10.70 \pm 1.0$ & $11.60 \pm 1.5$ \\
\hline P. micra & $12.50 \pm 1.5$ & $11.90 \pm 1.0$ & $11.30 \pm 0.6$ & $14.90 \pm 0.9$ & $15.20 \pm 1.4$ & $21.80 \pm 0.7$ \\
\hline P. gingivalis & $14.30 \pm 0.3$ & $7.40 \pm 0.5$ & $10.90 \pm 0.4$ & $14.70 \pm 1.8$ & $14.50 \pm 1.2$ & $22.10 \pm 1.2$ \\
\hline P. nigrescens & $13.20 \pm 1.2$ & $7.60 \pm 0.6$ & $11.20 \pm 0.7$ & $14.40 \pm 1.1$ & $15.20 \pm 0.5$ & $21.10 \pm 0.4$ \\
\hline $\begin{array}{l}\text { Average values of each } \\
\text { substance against all } \\
\text { microorganisms tested }\end{array}$ & $9.16 \pm 4.0^{b}$ & $8.68 \pm 2.0^{b}$ & $8.99 \pm 2.2^{b}$ & $11.95 \pm 3.6^{b}$ & $9.91 \pm 4.7^{b}$ & $16.28 \pm 5.4^{a}$ \\
\hline
\end{tabular}

Different letters $(a, b)$ indicate statistically significant values $(p<0.05)$

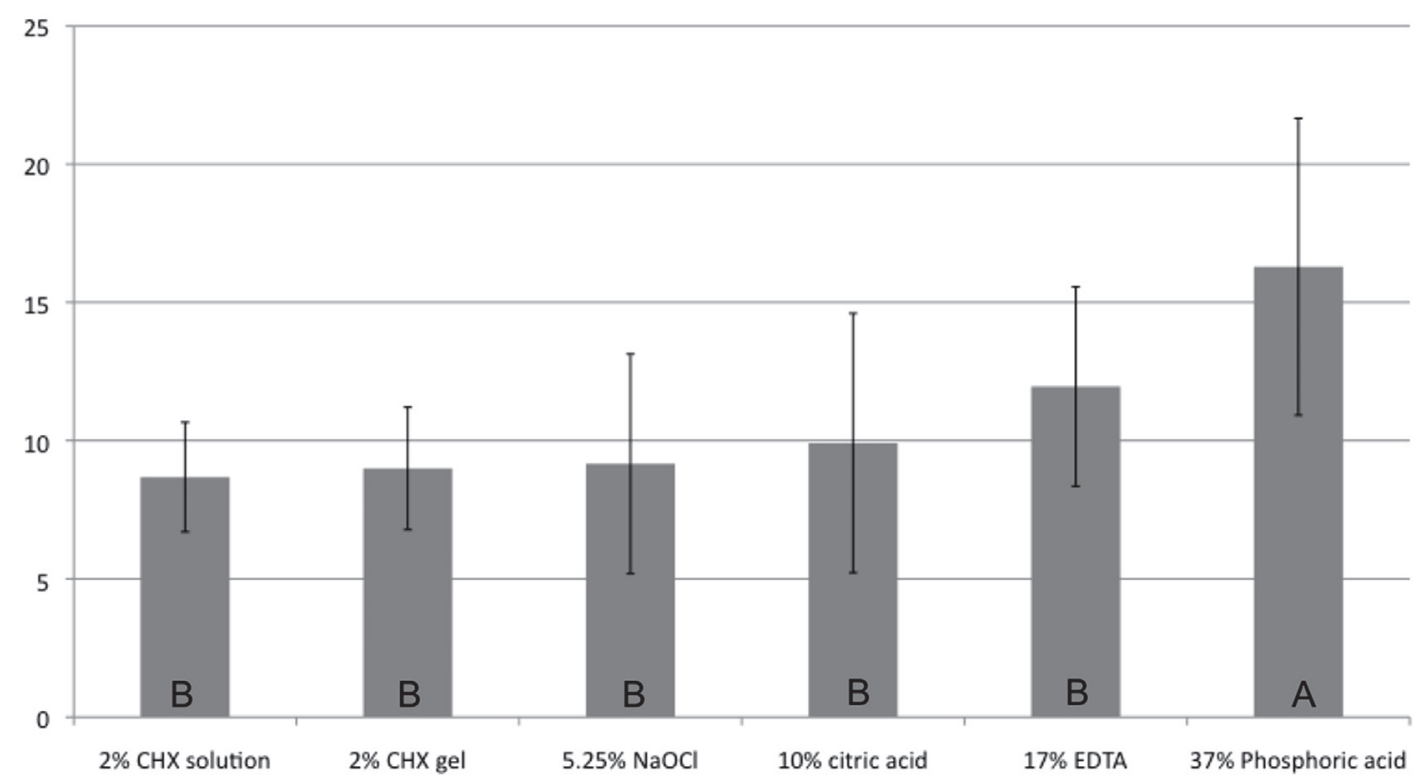

Figure 1-Values of growth inhibition zones $(\mathrm{mm})$ for the eight tested microorganisms Note: Different letters indicate statistically significant values $(p<0.05)$ 


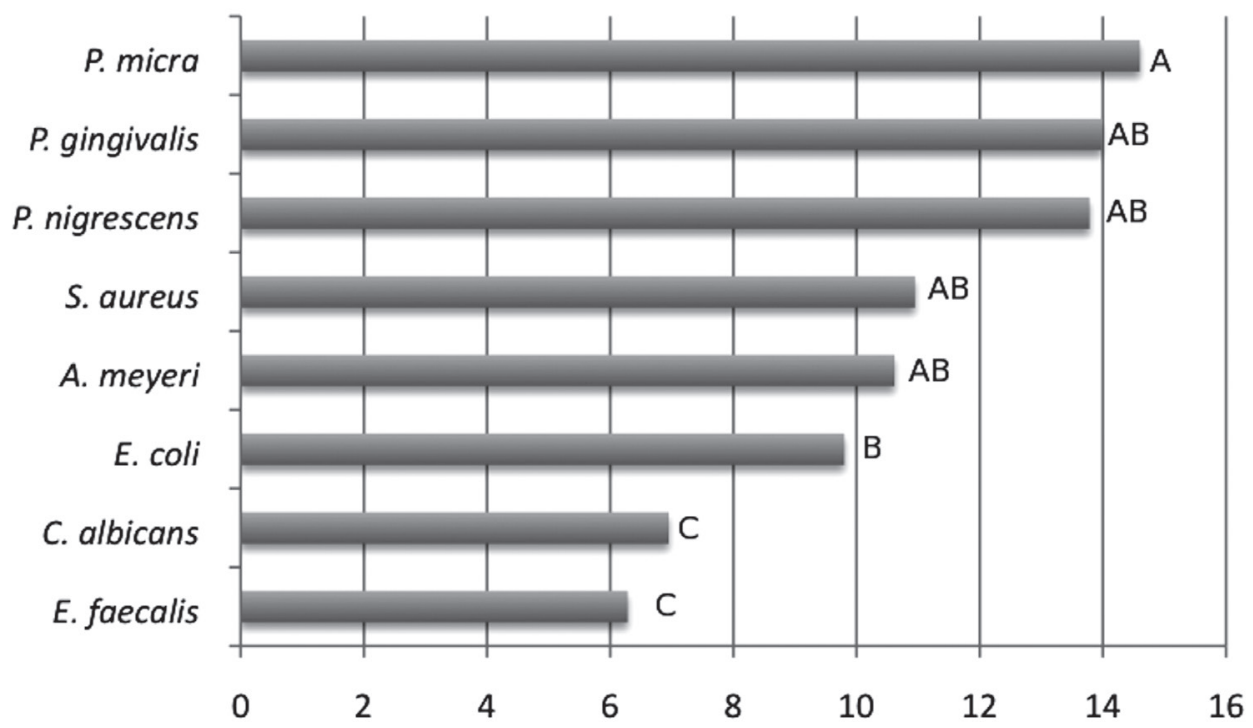

Figure 2- Average (in $\mathrm{mm}$ ) of the zones of inhibition of each microorganism against all irrigants tested Note: Different letters indicate statistically significant values $(p<0.05)$

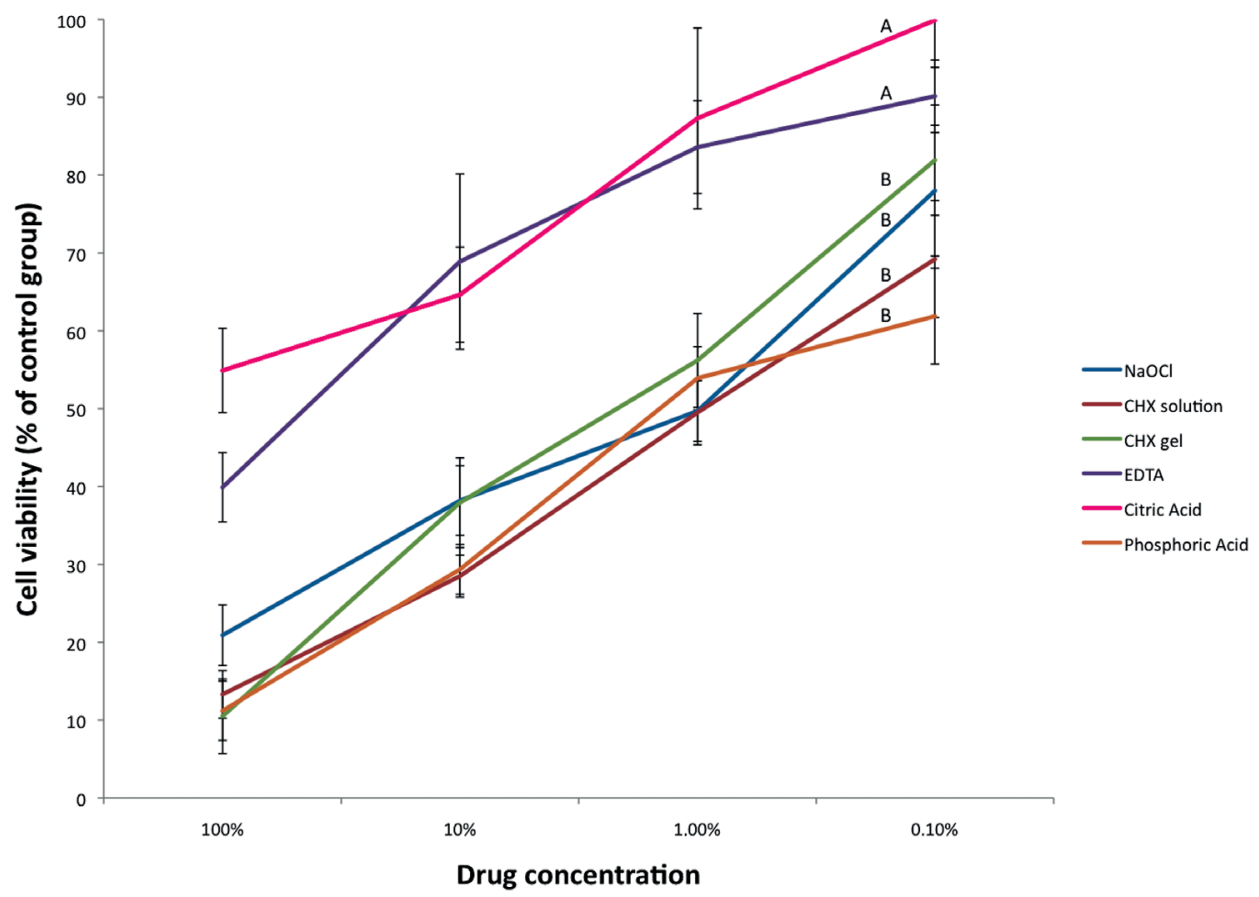

Figure 3- Cell viability to the tested irrigants

Note: Different letters indicate statistically significant values $(p<0.05)$

Figure 3 shows the cell viability of the different irrigants. Statistically, 37\% phosphoric acid showed cell viability similar to that of $5.25 \% \mathrm{NaOCl}, 2 \%$ chlorhexidine (gel and solution), whereas $17 \%$ EDTA and $10 \%$ citric acid showed higher cell viability than the other irrigants.

\section{DISCUSSION}

The need for removing smear layer seems to be a consensus in the literature $\mathrm{e}^{4,13,19}$ for several reasons, including: a) it contains bacteria and necrotic tissues; b) it forms a barrier between the filling material and sound dentin that limits the penetration of irrigants/ medicaments and sealers into dentinal tubules; c) it increases microleakage with commonly used sealers; d) it decreases the bond strength of resin based materials.

The solution of $37 \%$ phosphoric acid has been found to be effective as a final rinse substance to remove the smear layer from the instrumented surface of root canals and to prevent the formation of a chemical smear layer when used as intermediate irrigant between sodium hypochlorite and chlorhexidine ${ }^{13,14}$. Additionally, it can increase the resin-based sealer bond strength to dentin ${ }^{13}$. 
However, apart from its chemical properties, it should also have strong antimicrobial properties and minimal cytotoxic effects on the periradicular tissues. The present work compared the antimicrobial and cytotoxic effects of a $37 \%$ phosphoric acid solution to other irrigants commonly used in endodontics, including $5.25 \% \mathrm{NaOCl}, 2 \%$ chlorhexidine (solution and gel), 17\% EDTA, and 10\% citric acid.

The agar diffusion test, used in the present study, is a worldwide accepted procedure for determining the in vitro sensitivity under routine laboratory conditions. This method is simple, standardized, and reproducible, being used in several studies, not only to test the antimicrobial properties of irrigants ${ }^{5,18,21}$, but also of intracanal medicaments ${ }^{7}$ and sealers ${ }^{17}$.

In the present study, E. faecalis and C. albicans were the microorganisms showing the smallest inhibition zone against all tested irrigants, while strict anaerobes such as the Gram-positive $P$. micra and the Gram-negative bacteria such as $P$. gingivalis, and $P$. nigrescens showed the largest inhibition zones. It could be extrapolated that even though the anaerobic bacteria, such as Parvimonas, Prevotella or Porphyromonas spp. are associated with painful infectious exacerbations ${ }^{6,21}$, they are more susceptible to the tested irrigants. On the other hand, facultative Gram-positive bacteria such as $E$. faecalis and C. albicans, which have been associated with asymptomatic root canals ${ }^{6,21}$, seem to be more resistant to root canal therapy and are therefore related to endodontic failures. Our findings are in agreement with the literature ${ }^{6,21}$. Further investigations using a biofilm model and confocal laser scanning microscopy (CLSM) in order to detect and quantify the bacterial viability after the use of these tested irrigants are required to confirm these preliminary results.

Additionally, all irrigants had an antimicrobial effect on the eight tested strains. However, phosphoric acid showed the highest antimicrobial activity compared to the other irrigants evaluated. The action mechanism of phosphoric acid has not been fully elucidated. One possible explanation is that it may act by increasing the hydrogen-ion concentration in the microorganism, which cannot maintain their vitality under these conditions ${ }^{2,15}$. With regard to this aspect, it was observed that the bactericidal activity of $5 \%$ phosphoric acid and $10 \%$ citric acid was similar, with the former requiring less time than the latter to exert its antimicrobial activity ${ }^{2}$. Regarding the values found for $5.25 \% \mathrm{NaOCl}$ and $2 \%$ $\mathrm{CHX}$, they are similar to those reported by Ferraz, et al. ${ }^{5}$ (2007), but differ from Siqueira, et al. ${ }^{18}$ (1998).

The cytotoxicity of the irrigants to $3 \mathrm{~T} 3$ fibroblast cells was evaluated here. Studies on established cell lines are used because of the reproducibility of the results, besides the fact that they multiply rapidly and have unlimited life $\operatorname{span}^{3,8,16}$. Our results revealed that the cytotoxicity of the $37 \%$ phosphoric acid solution was higher than that of other solutions employed for removal of smear layer, such as $17 \%$ EDTA and $10 \%$ citric acid. However, EDTA and citric acid showed similar cytotoxic effects, which is in disagreement with other studies that observed a lower cytotoxic effect for the citric acid ${ }^{1,9}$.

In addition, phosphoric acid showed a similar cytotoxicity compared to $5.25 \% \mathrm{NaOCl}$ and $2 \%$ chlorhexidine (solution and gel), in accordance with a previous study ${ }^{4}$ that compared $\mathrm{NaOCl}$ and chlorhexidine. However, our findings differ from others that observed a lower cytotoxic effect for $2 \%$ chlorhexidine ${ }^{11}$. No study was found in the literature comparing the cytotoxicity of phosphoric acid with other endodontic irrigants.

\section{CONCLUSION}

The solution of $37 \%$ phosphoric acid exhibited antimicrobial effect against the tested endodontics pathogens and cytotoxicity similar to that of 5.25\% $\mathrm{NaOCl}$ and $2 \%$ chlorhexidine (solution and gel).

\section{ACKNOWLEDGEMENTS}

This study was supported by the Brazilian funding agencies: FAPESP - São Paulo Research Foundation (protocol numbers 2009/53976-0, 2010/50817-5 and 2011/09047-4), CNPq - National Council for Scientific and Technological Development (protocol number 302575/2009-0) and CAPES - Coordination for the Improvement of Higher Education Personnel.

\section{REFERENCES}

1- Amaral KF, Rogero MM, Fock RA, Borelli P, Gavini G. Cytotoxicity analysis of EDTA and citric acid applied on murine resident macrophages culture. Int Endod J. 2007;40:338-43.

2- Arias-Moliz MT, Ferrer-Luque CM, Espigares-Rodríguez E, Liébana-Ureña J, Espigares-García M. Bactericidal activity of phosphoric acid, citric acid, and EDTA solutions against Enterococcus faecalis. Oral Surg Oral Med Oral Pathol Oral Radiol Endod. 2008;106:e84-9.

3- Bouillaguet S, Wataha JC, Tay FR, Brackett MG, Lockwood PE. Initial in vitro biological response to contemporary endodontic sealers. J Endod. 2006;32:989-92.

4- Chang YC, Huang FM, Tai KW, Chou MY. The effect of sodium hypochlorite and chlorhexidine on cultured human periodontal ligament cells. Oral Surg Oral Med Oral Pathol Oral Radiol Endod. 2001;92:446-50.

5- Ferraz CC, Gomes BP, Zaia AA, Teixeira FB, Souza-Filho FJ. Comparative study of the antimicrobial efficacy of chlorhexidine gel, chlorhexidine solution and sodium hypochlorite as endodontic irrigants. Braz Dent J. 2007;18:294-8.

6- Gomes BP, Ferraz CC, Garrido FD, Rosalen PL, Zaia AA, Teixeira FB, et al. Microbial susceptibility to calcium hydroxide pastes and their vehicles. J Endod. 2002;28:758-61.

7- Koo H, Gomes BP, Rosalen PL, Ambrosano GM, Park YK, Cury JA. In vitro antimicrobial activity of propolis and Arnica montana against oral pathogens. Arch Oral Biol. 2000;45:141-8. 
8- Loushine BA, Bryan TE, Looney SW, Gillen BM, Loushine RJ, Weller RN, et al. Setting properties and cytotoxicity evaluation of a premixed bioceramic root canal sealer. J Endod. 2011;37:673-7. 9- Malheiros CF, Marques MM, Gavini G. In vitro evaluation of the cytotoxic effects of acid solutions used as canal irrigants. ] Endod. 2005;31:746-8.

10- McComb D, Smith DC. A preliminary scanning electron microscopic study of root canals after endodontic procedures. J Endod. 1975;1:238-42.

11- Onçağ O, Hoşgör M, Hilmioğlu S, Zekioğlu O, Eronat C, Burhanoğlu D. Comparison of antibacterial and toxic effects of various root canal irrigants. Int Endod J. 2003;36:423-32.

12- Prado M, Gusman H, Gomes BP, Simão RA. Scanning electron microscopic investigation of the effectiveness of phosphoric acid in smear layer removal when compared with EDTA and citric acid. J Endod. 2011;37:255-8.

13- Prado M, Simão RA, Gomes BP. Effect of different irrigation protocols on resin sealer bond strength to dentin. J Endod. 2013;39:689-92.

14- Prado M, Simão RA, Gomes BP. Evaluation of different irrigation protocols concerning the formation of chemical smear layer. Microsc Res Tech. 2013;76:196-200.

15- Russel AD, Hugo WB, Ayliffe GA. Principles and practice of disinfection, preservation and sterilization. $3^{\text {rd }}$ ed. Oxford: Blackwell Science Ltd; 1999. p. 124-48.
16- Schwarze T, Leyhausen G, Geurtsen W. Long-term cytocompatibility of various endodontic sealers using a new root canal model. J Endod. 2002;28:749-53.

17- Silva EJ, Herrera DR, Rosa TP, Duque TM, Jacinto RC, Gomes BP, et al. Evaluation of cytotoxicity, antimicrobial activity and physicochemical properties of a calcium aluminate-based endodontic material. J Appl Oral Sci. 2014;22:61-7.

18- Siqueira JF Jr, Batista MM, Fraga RC, de Uzeda M. Antibacterial effects of endodontic irrigants on black-pigmented gram-negative anaerobes and facultative bacteria. J Endod. 1998;24:414-6.

19- Torabinejad M, Handysides R, Khademi AA, Bakland LK. Clinical implications of the smear layer in endodontics: a review. Oral Surg Oral Med Oral Pathol Oral Radiol Endod. 2002;94:658-66. 20- Torabinejad M, Shabahang S, Aprecio RM, Kettering JD. The antimicrobial effect of MTAD: an in vitro investigation. J Endod. 2003;29:400-3.

21- Vianna ME, Gomes BP, Sena NT, Zaia AA, Ferraz CC, Souza Filho FJ. In vitro evaluation of the susceptibility of endodontic pathogens to calcium hydroxide combined with different vehicles. Braz Dent J. 2005; 16:175-80.

22- Zehnder M. Root canal irrigants. J Endod. 2006;32:389-98. 